\title{
Refuse-derived fuel classification in a mechanical-biological treatment plant and its valorization with techno-economic criteria
}

\author{
P. Vounatsos • M. Agraniotis • P. Grammelis • \\ E. Kakaras $\cdot$ O. Skiadi $\cdot$ T. Zarmpoutis
}

Received: 12 March 2013/Revised: 17 June 2013/Accepted: 11 January 2014/Published online: 4 February 2014

(C) Islamic Azad University (IAU) 2014

\begin{abstract}
Refuse-derived fuels (RDF) are a category of alternative fuels produced as byproducts from the process of waste management plants. RDF can be utilized for heat and power production, contributing to the waste hierarchy set by European Union. However, the need for standardization of RDF becomes gradually important in SouthEastern Europe, where the market for waste recovered fuels is under development. The application of certification and quality management schemes in the waste treatment and fuel production processes, along with the use of a new terminology, solid recovered fuels may enhance public acceptance and promote the thermal utilization of this resource in industrial facilities. In the present work, a sampling and analysis campaign of RDF produced at a mechanical and biological treatment facility in Athens, Greece, took place. The sampling and analysis were carried out according to the standards of CEN/TC 343. The sampling period lasted 1 year, resulting in 20 samples. Proximate, ultimate analysis, chlorine and heavy metals' content were carried out. Furthermore, a technical and economic assessment was carried out, in order to propose realistic solutions for the improvement of the produced RDF quality and the plants' viability. Two sets of scenarios are assessed with techno-economic criteria referring to different technical solutions. At the end of the study, a step-by-step
\end{abstract}

P. Vounatsos $(\bowtie) \cdot$ M. Agraniotis · P. Grammelis · E. Kakaras Chemical Process and Energy Resources Institute, Centre for Research and Technology Hellas, 4th km. N.R. Ptolemais, Kozani, 50200 Ptolemais, Greece

e-mail: vounatsos@certh.gr

O. Skiadi · T. Zarmpoutis

Association of Communities and Municipalities of the Attica Region, Andersen 6 \& Moraiti 90, 11525 Athens, Attica, Greece approach is proposed, which may guarantee the economic feasibility of the proposed plant retrofitting project and a pay-back period adjusted to the extent of the retrofitting measures to be decided.

Keywords Secondary fuels - "EMA" plant - Chemical analyses $\cdot$ Characterization $\cdot$ Feasibility study

\section{Introduction}

Municipal solid waste (MSW) treatment in Greece and in South-Eastern Europe is still dominated by the least preferable practices according to European waste treatment hierarchy, i.e., land-filling instead of materials and energy recovery. This in turn leads to low shares of recycled materials and waste recovered fuel production in comparison with the overall MSW production. Waste recovered fuels—or so-called refuse-derived fuels, (RDF) - are the remaining fraction of a material recovery process and are produced in mechanical-biological treatment (MBT) plants utilizing MSW as inlet materials, as well as in material recovery facilities (MRF) utilizing packaging waste as inlet materials. The promotion of standardization practices for refuse-derived fuels has led to the adoption of new European Standards according to the work of the CEN Technical Committee 343. Based on this work, waste recovered fuels, which fulfill specific standards regarding fuel parameters (net calorific value, chlorine content and Mercury concentration) and quality assurance schemes during their production process, can be characterized with the term "solid recovered fuels, SRF." This standardization process facilitates their public acceptance, supports the development of quality assurance mechanisms and enhances the marketability of the particular fuel streams. 
There have been numerous studies on the analysis of RDF depending on various parameters of interest such as the biomass content, ash characterization and aerodynamic classification of RDF. (Fellner and Rechberger 2009; Fellner et al. 2011; Dunnu et al. 2006; Dunnu et al. 2010; Dunnu et al. 2009; Ollila et al. 2006). Yet until now, there have been only a few published studies referring to a complete sampling and analysis procedure, in order to classify RDF according to the European standards CEN/TC 343. Regarding the studied MBT plant named "EMA," a study on Life Cycle Assessment has been made (Abeliotis et al. 2012). There have also been studies on the design and cost of RDF production plants (Caputo and Pelagagge 2002), as well as identifying the energy content on the produced RDF from MBT plants (Uson et al. 2012).

As a consequence of the good energy content, RDF has been the center of a lot of research activity on defining its behavior on various thermal processes. Grammelis et al. (2009) have studied the pyrolysis kinetics and combustion characteristics of waste recovered fuels. Sorum et al. (2001) have studied the pyrolysis characteristics and kinetics of municipal solid wastes. There have been several other studies concentrating on the characteristics and kinetics of the reactions taking place during thermal utilization of RDF. (Henrich et al. 1999; Cozzani et al. 1995; Lin et al. 1999; Kim 2001; Garcia et al. 1995)

Moreover, there have been studies on RDF utilization in large scale. Hilber et al. (2007) have studied the advantages and possibilities of RDF co-combustion in European energy sector, while Agraniotis et al. (2010) studied a model of SRF co-firing with brown coal in large-scale boilers. Finally, Hernadez-Atonal et al. (2007) presented their work on the combustion of RDF in a fluidized bed. This indicates an international mobilization in producing and utilizing RDF as a substitute fuel, making the standardization of RDF not an option but a necessity.

For the outcome of the present work, the sampling procedure lasted 1 year from October 2010 until September 2011 and a total of twenty (20) samples were gathered and analyzed. This corresponds to about one sample for analysis per 2 weeks.

\section{Materials and methods}

\section{Facility description}

The Association of Communities and Municipalities of the Attica Region (ACMAR) has implemented a complete project of waste treatment in Attica. The Plant of Mechanical Recycling and Composting (called "EMA") of Ano Liossia occupies an area of about 150 acres, and every day it treats 1,200 t of municipal solid waste (MSW), in which an increasing amount of biomass residues of $30 \mathrm{t} /$ day are found. Moreover, there is an input of about $300 \mathrm{t} /$ day of sludge and $130 \mathrm{t} /$ day of prunings. It produces RDF, some recyclable materials, compost and residues for the landfill located near the plant. The technology used belongs to the Mechanical and Biological Treatment (MBT) category and more specifically to the subcategory of the plants that use the organic content of MSW for composting instead of incorporating it stabilized into the produced RDF. (Sipsas et al. 2008)

Sampling and analyses

The scope of the sampling procedure implemented was to classify the RDF produced from the "EMA" according to European Standards produced from the Technical Committee CEN/TC 343. More specifically, the following analyses were conducted:

1. Proximate analysis (Moisture, Ash, Volatiles, Char)

2. Ultimate analysis $(\mathrm{C}, \mathrm{H}, \mathrm{N}, \mathrm{S}, \mathrm{O}, \mathrm{Cl})$

3. Heating Value analysis (HHV, LHV or GCV, NCV)

4. Heavy metals analysis $(\mathrm{Sb}, \mathrm{Cd}, \mathrm{Cr}, \mathrm{Co}, \mathrm{Cu}, \mathrm{Pb}, \mathrm{Mn}$, $\mathrm{Hg}, \mathrm{Ni}, \mathrm{Tl}, \mathrm{V}$ )

\section{Planning of sampling procedure}

During the material recycling procedure of "EMA," there is the production of RDF which is mainly comprised of plastic, paper, textile and other light fractions of the MSW. This secondary fuel is coming out of the ballistic separators as the light fraction (thin and light material) and is driven into shredders, where the material is cut into smaller pieces at the size of $70 \times 70 \mathrm{~mm}^{2}$, producing a fluff material with low density.

According to the standard (EN 15442:2011), there are certain conditions regarding sample and lot mass that must be taken into account in order to consider that a sample is representative for a batch of produced RDF.

Applying the instructions of the standard to the needs and the setup of "EMA" plant, a lot size of 1,050 t of produced RDF is decided, from which a representative sample was gathered. During this period, it was decided that the combined sample would be composed of 24 increments taken in random hours within a day. The parameters of the sampling procedure designed are the following:

- Lot size: $1,050 \mathrm{t}$

- Sampling procedure: manually from drop flow

- Number of Increments: 24

- Increment size: $104 \mathrm{~g}$

- Sample size: $2.5 \mathrm{~kg}$ 
Sample pre-treatment

For the effective storage and analysis of the samples and according to the standard (EN 15443:2011), the final sample is pre-dried to a total moisture of less than $10 \%$ and then grinded. Low-temperature drying is used for the sole purpose of removing a quantity of water that could influence the grinding effectiveness and affect the longterm storage of the sample. The grinding must be avoided when the nature of the sample prohibits it, e.g., very soft materials. However, in our case, in order to prepare the sample for laboratory analysis, the sample is grinded in two steps, first down to $10 \mathrm{~mm}$ and afterward to a final diameter of less than $0.5 \mathrm{~mm}$. This practice was found to save about $2 \mathrm{~h}$ per kilo of sample grinded.

\section{Analyses}

For the determination of the moisture content, a simplified drying procedure is followed as is described in the standard (EN 15414-3:2011). The moisture percentage is calculated as the difference between the mass weighted before and after drying. For the determination of the volatiles, the standard (EN 15402:2011) is followed. The ash analysis is made under the standard (EN 150403:2011), while the char is calculated as the difference between the whole mass and the percentages of moisture, ash and volatiles.

Regarding the ultimate analysis $(\mathrm{C}, \mathrm{H}, \mathrm{N}, \mathrm{S}, \mathrm{Cl}, \mathrm{O})$, an elemental analyzer is used (model $2400 \mathrm{CHNS} / \mathrm{O}$ Series II Perkin Elmer) with the choice of simultaneous analysis of the elements $\mathrm{C}, \mathrm{H}, \mathrm{N}, \mathrm{S}$. For the determination of the aforementioned elements, the standard (EN 15407:2011) is used, while for the determination of $\mathrm{Cl}$ content, the instructions of (EN 15408:2011) are followed.

As far as the heating value is concerned, the sample was first grinded to a final particle size below $0.25 \mathrm{~mm}$, and then it was analyzed according to the standard (EN 15400:2011). The calorimeter Leco AC-350 was used for the analysis.

For the determination of heavy metals, the first step of the methodology is the low-temperature ashing of the sample. Then the sample undergoes a digestion in microwaves. After the digestion, it is filtered and diluted. The measurement of the trace elements is done using the method of atomic absorption spectroscopy with graphite (GF-AAS) according to the standard (15411:2011). The instrument used is Shimadzu AA-6300 Atomic Absorption Spectrophotometer with GFA-EX7i Graphite Furnace Atomizer.

During the sampling and analysis procedure, as well as the sample pre-treatment stage, all the necessary precautions have been taken for health safety according to the European norms.
Proposals for RDF and process improvement

To this day, there is not a sustainable and healthy market for RDF end users in Greece, while the produced RDF in "EMA" does not make an exception in terms of its thermal utilization. The scope of this part of the study is to investigate ways to improve the quality of the produced RDF in order to increase its acceptability from end users and at the same time to improve the economical viability of the MBT plant "EMA," through a techno-economical analysis. The analysis is divided in scenarios of continuously increasing complexity.

As mentioned, a part of the scope is to achieve the plants' viability. The scenarios are divided in two subgroups, depending on the material stream of the plant that is under investigation each time. As referred by the Greek Ministry of Environment, Energy and Climate Change, the MSW stream in Greece contains a high fraction of plastic and paper, most of which is not separated at the source and is of high added value.

Considering the circumstances, the first group of scenarios studied the heavy stream separated from the ballistic classifiers. That stream is where a very high percentage of heavy plastic fractions - which are of high added valueend. The group is divided in three sub-scenarios. The first scenario (Scenario A1) identifies the revenues resulting from recovering a stream of small mass yet very high added value plastic (PET), utilizing one optical separator dedicated in PET picking. The second scenario (Scenario A2) is a comparative scenario to the first, by studying the recovery of a high mass and low added value mixed plastic stream including PET, HDPE and PP, utilizing one optical separator dedicated in plastics picking. The final scenario (Scenario A3) studies the separate recovery of both high and low added value streams (PET, HDPE, PP), utilizing three optical separators dedicated in plastics picking. These cases were studied within the scope of improving the economical viability of the "EMA" plant.

The second group of scenarios studied the most possibly economical scenario for RDF management, taking into account the present operating situation of the "EMA" plant. The first scenario (Scenario B1) studied is the management scheme with no possible end users, which is land-filling and is regarded as a base case scenario. In this particular scenario, no utilization for the RDF is examined; therefore, the assumption of direct land-filling is taken into consideration. The second scenario (Scenario B2) studied the utilization of RDF in industries without any pre-treatment. An assumption made for this scenario is that the produced RDF will meet the standards set by the end users (such as cement and lime industries in Greece) without any pre-treatment for its quality upgrade. The third scenario (Scenario B3) studied the utilization of RDF in industries after it has been dried in the plant of "EMA." The 
Table 1 Technical and economic parameters taken into consideration

\begin{tabular}{ll}
\hline Parameter & Value \\
\hline Daily MSW input for treatment and produced & $1,200 \mathrm{t} \mathrm{MSW}-$ \\
RDF & $450 \mathrm{t} \mathrm{RDF}$ \\
Plant working hours/day & $10 \mathrm{~h} /$ day \\
Working days/year & 252 days/year \\
Approximate PET concentration in MSW input & $1.5 \%$ \\
Approximate HDPE concentration in MSW & $1.5 \%$ \\
input & \\
Approximate PP concentration in MSW input & $1 \%$ \\
PET, HDPE and PP percentage separated from & $86 \%$ \\
$\quad$ ballistic separators & \\
Approximate PET selling price & $350 € / \mathrm{t}$ \\
Approximate HDPE selling price & $180 € / \mathrm{t}$ \\
Approximate PP selling price & $180 € / \mathrm{t}$ \\
Approximate plastic mixture selling price & $100 € / \mathrm{t}$ \\
Estimation of CHP boiler costs & $1 \mathrm{mio} / \mathrm{MWth}_{\mathrm{in}}$ \\
Estimation of drier costs & $350.000 € / \mathrm{tnH}_{2} 0$ \\
Estimation of maintenance and labor costs & $3 \%$ of investment \\
Landfill cost & $\mathrm{cost}$ \\
Gate fee & $45 € / \mathrm{tn} \mathrm{RDF}$ \\
Power selling price assumption & $35 € / \mathrm{tn} \mathrm{RDF}$ \\
Inflation rate & $88 € / \mathrm{MWh}$ \\
Discount rate & $3 \%$ \\
Revenues tax & $5 \%$ \\
\hline & $25 \%$ \\
\hline
\end{tabular}

heat required for the drying procedure will be taken from the waste heat of nearby facilities which are already installed and their waste heat can cover the thermal needs of the dryer. The fourth and final scenario (Scenario B4) studied the mass incineration of RDF in a dedicated combined heat and power (CHP) boiler which will be installed as an expansion of the "EMA" plant. All the prices for the necessary equipment were calculated according to offers gathered from manufacturing companies. All other costs and expenditures were calculated according to data acquired from ACMAR. In all the aforementioned scenarios, the maintenance, labor and waste management costs were included in the study. The scenarios analysis was made by the assumption of making the investment only with own funds. In Table 1, all the economic and technical parameters taken into consideration are presented.

\section{Results and discussion}

Analyses

For the sampling campaign of twenty lots, the analyses results are presented and discussed in the following paragraphs.
Table 2 Proximate analysis of RDF produced in "EMA" plant

\begin{tabular}{lcc}
\hline & Mean value & SD \\
\hline Moisture & 41.67 & 2.87 \\
Ash (wt\% raw) & 9.70 & 1.33 \\
Volatiles (wt\% raw) & 46.26 & 3.61 \\
Char(wt\% raw) & 2.37 & 1.64 \\
Ash (wt\% dry basis) & 16.65 & 2.33 \\
\hline
\end{tabular}

According to the results of proximate analysis (Table 2), the mean value of moisture is $41.67 \%$, with standard deviation of $2.87 \%$. This indicates that the produced RDF has significantly higher moisture content than other RDF samples studied. (Liu et al. 2001; Wan et al. 2008; Montejo et al. 2011)

More specifically, from the pre-drying procedure followed for all of the increments of each sample, moisture was found to be more than $32 \%$ in the majority of the samples. The maximum moisture found in a daily increment was $47.57 \%$, and the minimum was $31.60 \%$. The only sample that showed moisture of about $25 \%$ was taken in the day after the yearly plant maintenance. High moisture content is the most important factor that must be coped with, among the properties of RDF, because it influences the heating value in a great degree. In Fig. 1, the mean value of moisture content is depicted for each sample lot gathered.

Based on the data presented in Fig. 1 regarding moisture of samples, it must be noted that there are no great differences between the moisture of samples that are taken on dry (summer) and on wet (autumn-winter) periods. The highest moisture value was measured in a summer month, while the two lowest moisture values were measured in winter months. It is believed that the high moisture present in the summer months originates from the organic fraction with high moisture, which can be microscopically transferred to the paper of RDF during its stay in the bunker or in the trash bin. As far as winter/autumn months are concerned, there can be no possible distinction whether the moisture comes from open trash bins, while raining before the MSW is collected or not, because there is no actual log for when the bin is gathered. There is also a possibility that the MSW is dampened on purpose while in the garbage trucks in order to be better compacted.

Regarding ash content, the mean value was determined to be $9.70 \%$ with a standard deviation of $1.33 \%$. The maximum value measured was $13.23 \%$, and the minimum was $8.23 \%$. Ash originates mainly from the paper included in RDF samples as presented by the analyses of Grammelis et al. (2009), since as it can be concluded from Chiemchaisri et al. (2010) plastic bags, and generally other plastics include low amounts of ash. Ash percentage in RDF can be reduced by decreasing the content of papers in 


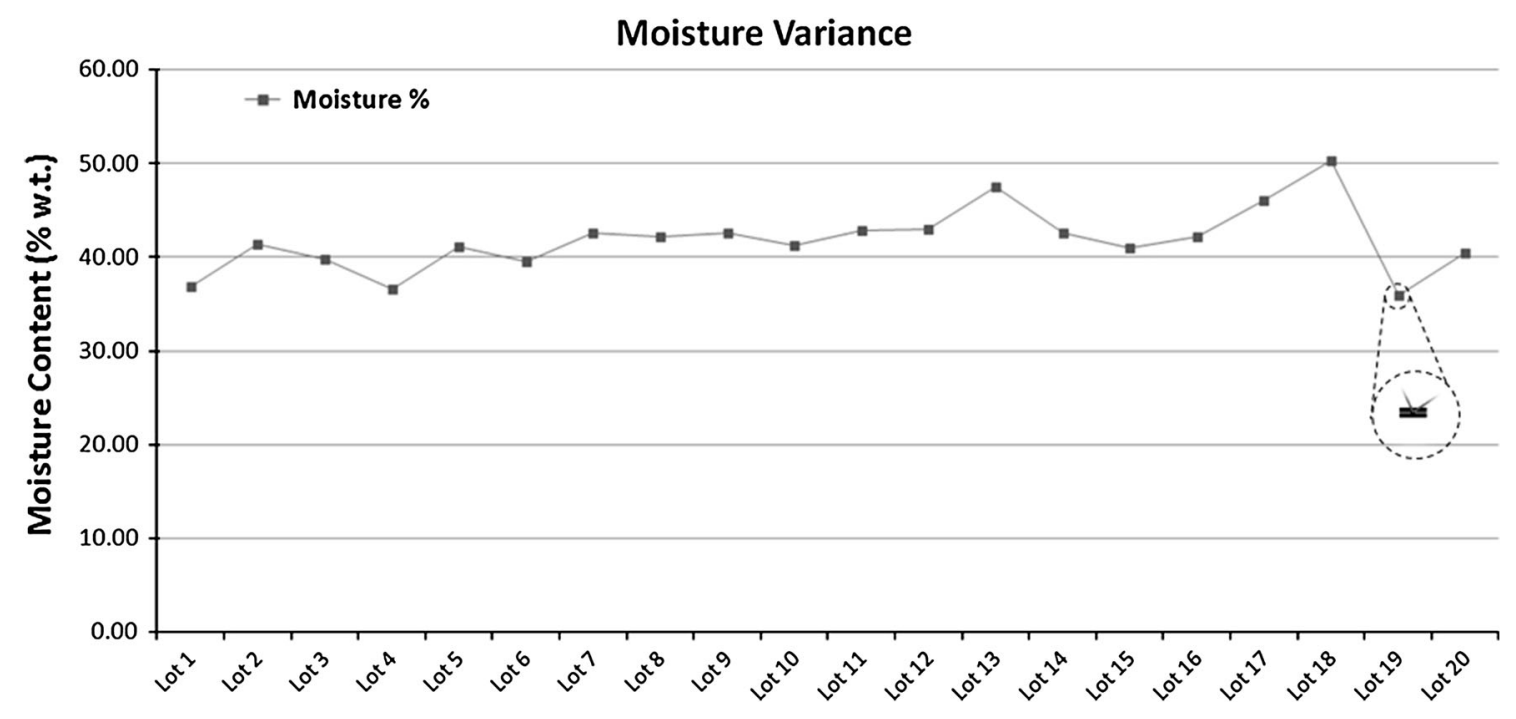

Fig. 1 Moisture variance

Fig. 2 Moisture content contribution of each material

\section{Contribution percentage of each material to the total moisture measured}

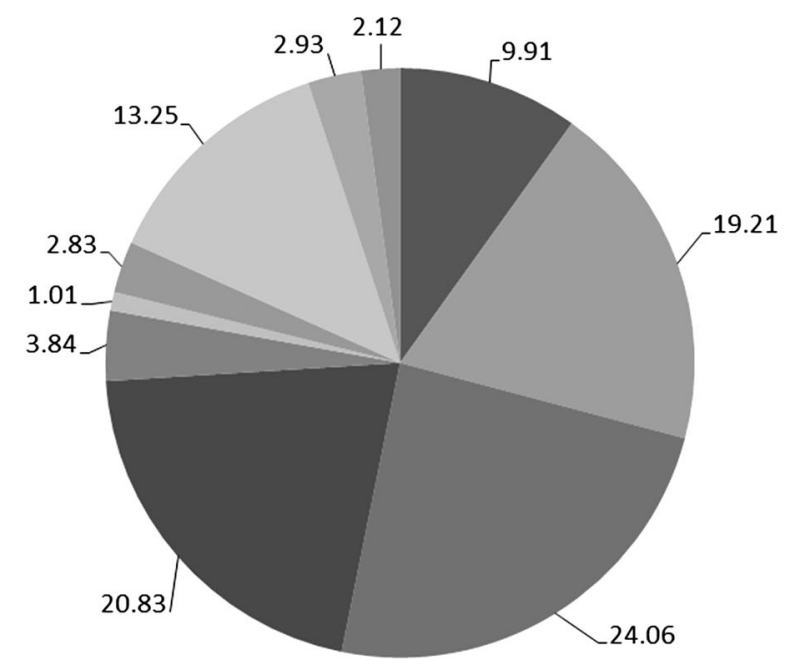

- Organincs

- Packaging paper

- Printed paper

Rest papers

Packaging plastics

Rest plastics

Textile

Wood

Metals

Rest
RDF while increasing the plastics content, respectively. Volatiles presented a maximum value of $51.46 \%$, and a minimum value of $35.89 \%$. Respectively, char presented a maximum of $4.74 \%$ and a minimum of $0.03 \%$.

In order to better indicate the source of moisture in the produced RDF, a manual sorting campaign took place separating RDF in 10 different materials. Afterward, the moisture of each material was measured, and in Fig. 2, the contribution of each material to the total moisture is depicted. This action was taken in order to find which materials contribute the most in the moisture content of the produced RDF. It was found that organics, all types of paper and wood contribute at a percentage of more than $85 \%$ to the total moisture of RDF.
The ultimate analysis mean value and standard deviation results are given in Table 3 as dry ash free in order to have a better overview of the content in elements. Chlorine is also presented in dry basis, so as to be used for the final classification of RDF according to the standard CEN 343. According to the analyses of Grammelis et al. (2009) and Wagland et al. (2011), it is believed that chlorine content originates mainly from PVC content, which is a part of MSW in small percentages. Generally, there are two major practices for PVC removal from MSW. The first one is hand picking of PVC containing materials during the MSW processing, while the second is the installation of a dedicated optical separator for PVC plastics removal. 
Table 3 Ultimate and heating value analysis of RDF produced in "EMA" plant

\begin{tabular}{lll}
\hline & Mean value & SD \\
\hline C (wt\% daf) & 57.06 & 3.02 \\
H (wt\% daf) & 7.60 & 0.46 \\
N (wt\% daf) & 1.64 & 0.42 \\
O (wt\% daf) & 0.18 & 0.21 \\
S (wt\% daf) & 32.67 & 3.34 \\
Cl (wt\% daf) & 0.85 & 0.20 \\
Cl (wt\% dry basis) & 0.71 & 0.17 \\
GCV (dry basis) $(\mathrm{MJ} / \mathrm{kg})$ & 21.79 & 1.98 \\
NCV (dry basis) $(\mathrm{MJ} / \mathrm{kg})$ & 20.40 & 2.02 \\
NCV (raw) $(\mathrm{MJ} / \mathrm{kg})$ & 10.87 & 1.17 \\
\hline
\end{tabular}

Chlorine is considered a technological indicator, and based on the dry basis mean value and standard deviation, the classification is made. According to the measured value, the RDF produced in "EMA" is classified as rank 3 (from scale 1-5) as a content in $\mathrm{Cl}$.

As seen in Fig. 3, there is an increase in dry basis net calorific value (NCV), from the middle of April and afterward. The error margin for the calculation of NCV based on the equipment used is about $0.21 \mathrm{~kJ} / \mathrm{kg}$. The factor that greatly affects NCV is moisture, and this is shown in summer months where the greatest reduction in $\mathrm{NCV}$ value is observed. As presented by Montejo et al. (2011), the found NCV can be comparable with the MSW analyses, on as received basis. Net calorific value is considered an economical indicator, and the classification according to CEN 343 is class 4 .
The analysis of heavy metals concentration in RDF is given in Table 4. It must be noted that heavy metal analysis is an extensive procedure with a lot of steps. A significant sensitivity of the outcome results has been observed, depending on the method of sample pre-treatment as well as the principle each instrument uses for the analysis. Mercury $(\mathrm{Hg})$ is also given in $\mathrm{mg} / \mathrm{MJ}$ raw, so as to be used for the final classification of RDF according to the standard CEN 343.

The variance of $\mathrm{Hg}$ concentration in $\mathrm{mg} / \mathrm{MJ}$ as received as well as the classification value is given in Fig. 4, with an error class of $0.28 \mathrm{ppb} / \mathrm{MJ}$ as derived from the measurement equipment. It is observed that four out of twenty values are higher than the rest, and despite the repetition of analysis to reduce the margin of error, the values measured represent reality, and there are no errors in the analysis procedure. A possible reason for high $\mathrm{Hg}$ concentrations in these samples is the existence of certain waste streams such as batteries, light bulbs and other mercury containing waste, which in case they are not separated in the source they can contaminate MSW with high heavy metal concentrations. The measured heavy metals can be comparable with the analyses presented by Wagland et al. 2011, on dry basis. Judging from this fact and according to the aforementioned author, the RDF produced in "EMA" could be suitable for utilization in fluidized bed combustors. According to CEN 343, the produced RDF is classified in category 1 as far as mercury content is concerned.

\section{Results for RDF and process improvement}

As described in the section materials and methods, the whole analysis is divided in two groups. The first group

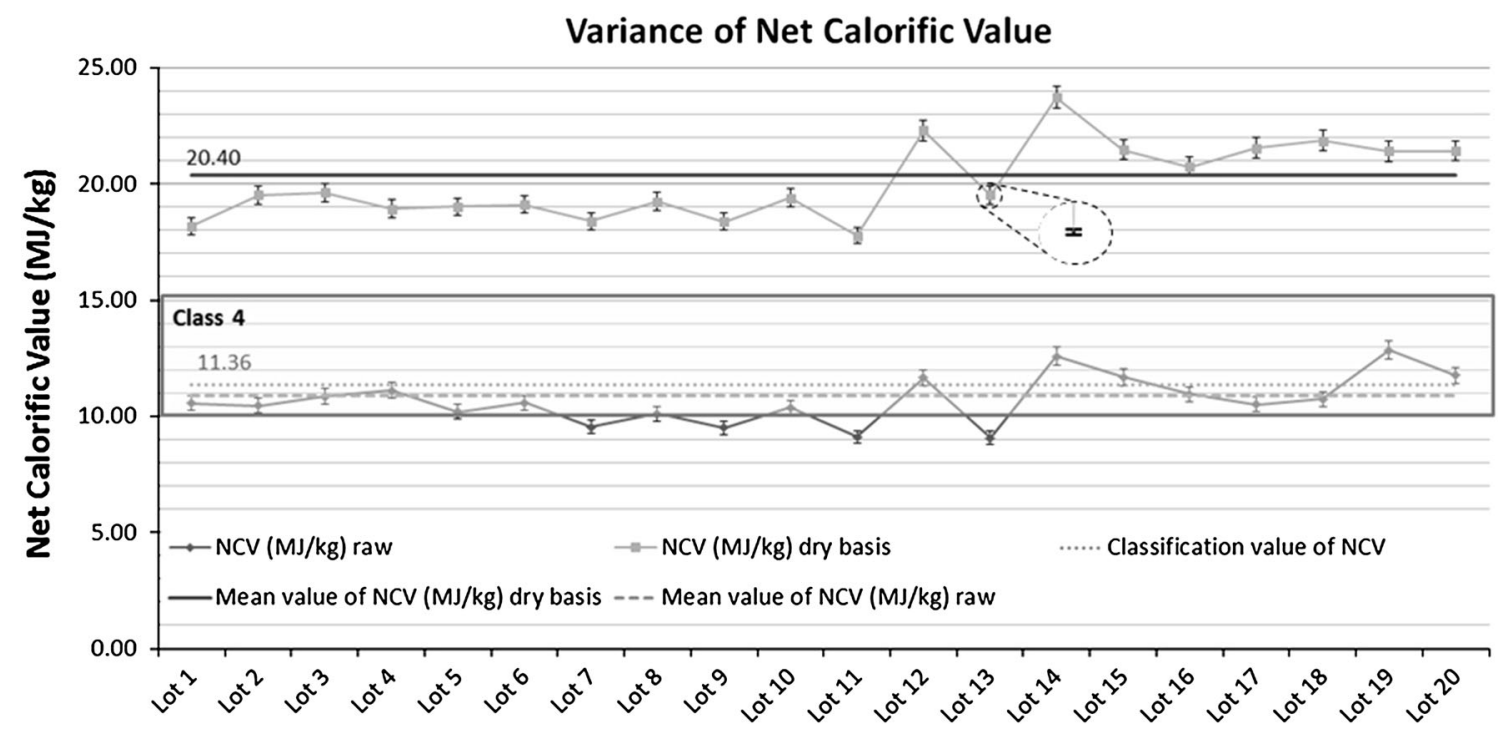

Fig. $3 \mathrm{NCV}$ variance as a function of sampling lots 
Table 4 Concentration in Heavy Metals of RDF produced in "EMA" plant

\begin{tabular}{|c|c|c|c|c|}
\hline & $\begin{array}{l}\text { Mean } \\
\text { value }\end{array}$ & SD & Median & $\begin{array}{l}\text { 80th } \\
\text { percentile }\end{array}$ \\
\hline $\mathrm{Sb}$ (mg/kg dry basis) & $<0.05$ & $<0.05$ & - & - \\
\hline As (mg/kg dry basis) & $<0.05$ & $<0.05$ & - & - \\
\hline Cd (mg/kg dry basis) & 4.59 & 3.02 & 6.08 & 6.74 \\
\hline $\mathrm{Cr}$ (mg/kg dry basis) & 18.37 & 8.43 & 16.20 & 25.39 \\
\hline Co (mg/kg dry basis) & 22.04 & 8.23 & 22.13 & 27.59 \\
\hline $\mathrm{Cu}$ (mg/kg dry basis) & 459.02 & 944.55 & 68.21 & 263.33 \\
\hline $\mathrm{Pb}$ (mg/kg dry basis) & 90.31 & 219.90 & 42.91 & 72.47 \\
\hline Mn (mg/kg dry basis) & 44.14 & 10.99 & 43.12 & 49.84 \\
\hline Hg (mg/kg dry basis) & 0.45 & 0.33 & 0.31 & 0.72 \\
\hline Ni (mg/kg dry basis) & 23.36 & 6.62 & 22.62 & 29.63 \\
\hline Tl (mg/kg dry basis) & 19.67 & 4.33 & 19.00 & 22.20 \\
\hline V (mg/kg dry basis) & $<0.05$ & $<0.05$ & - & - \\
\hline $\mathrm{Hg}$ (mg/MJ raw) & 0.0242 & 0.0180 & 0.0178 & 0.0345 \\
\hline
\end{tabular}

studies the recovery of plastics stream from the heavy stream of the ballistic classifier, and the second group studies management methods for the produced RDF. For the evaluation of the scenarios, the net present value (NPV) criterion was used for a 20-year period. A sum of the calculated investment costs, operational costs, yearly revenues as well as the capital recovery period is presented in Figs. 5 and 6, respectively, for set of scenarios A and B.

For the first group of scenarios, the factors that were considered were the investment cost, possible modifications in the plants modulation, as well as the power consumed by the optical separators. The economic factors (discount rate, inflation rate, revenues tax) were used according to the present situation in Greece. Moreover, it was assumed a 10-year life period for the optical separators, so after 10 years of life, they should be replaced.

In Fig. 5, the NPV analysis is shown. It is clearly shown that the least favorable scenario is $\mathrm{A} 2$, where there is the recovery of all the plastic streams together. On the contrary, the most favorable scenario of all is the recovery of each high added value stream separately, with a NPV of almost double worth in the passage of 20 years. These results may differ depending on the changes of input MSW stream to be processed in the "EMA" plant.

For the second group of scenarios, the factors that were considered were the investment cost, modifications in the plants modulation, gate fee for providing the end users with RDF, landfill cost, the ash management cost in case of mass incineration, and the price of selling electricity to the grid. The economic factors (discount rate, inflation rate, revenues tax) were used according to the present situation in Greece. Moreover, it was assumed a 10-year life period for the drier, and a 20-year life period for the CHP boiler.

In Fig. 6, the NPV analysis is shown. After the passage of 20 years, the least favorable scenario is B1, land-filling, indicating that apart from ecological disadvantages, it also has economical disadvantages in the depth of time. The most favorable scenario appears to be the incineration of RDF for electricity production, but the main disadvantage of this scenario is the very high initial investment cost. The second most favorable scenario is providing RDF to end users without any previous treatment. However, this scenario appeared to be somehow difficult for implementation due to the high moisture content of RDF. In that case, by drying the RDF, there are higher possibilities to be easily accepted from end users as a

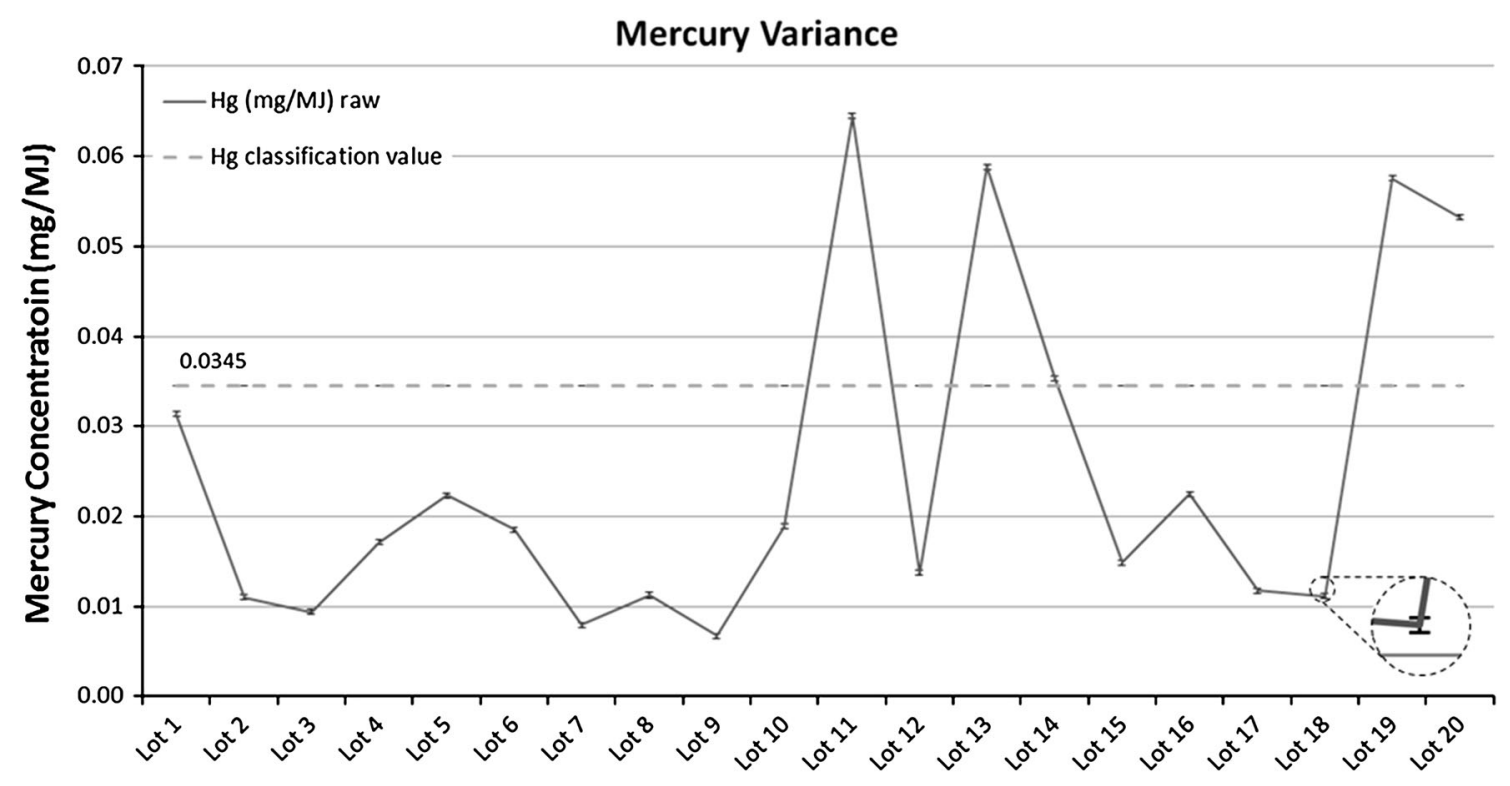

Fig. 4 Mercury variance as a function of sampling lots 


\section{Net Present Value Analysis}

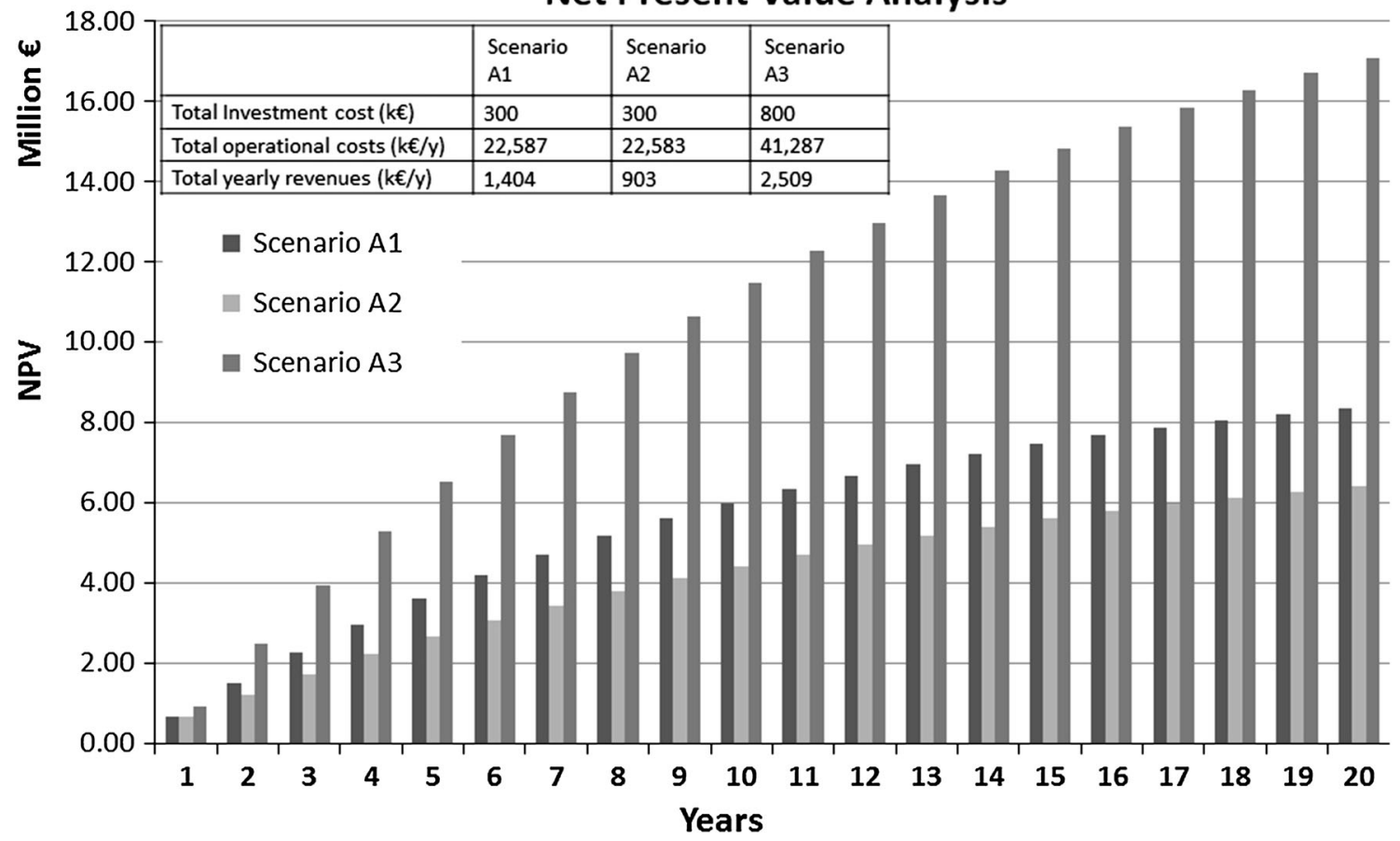

Fig. 5 NPV analysis for the first set of scenarios

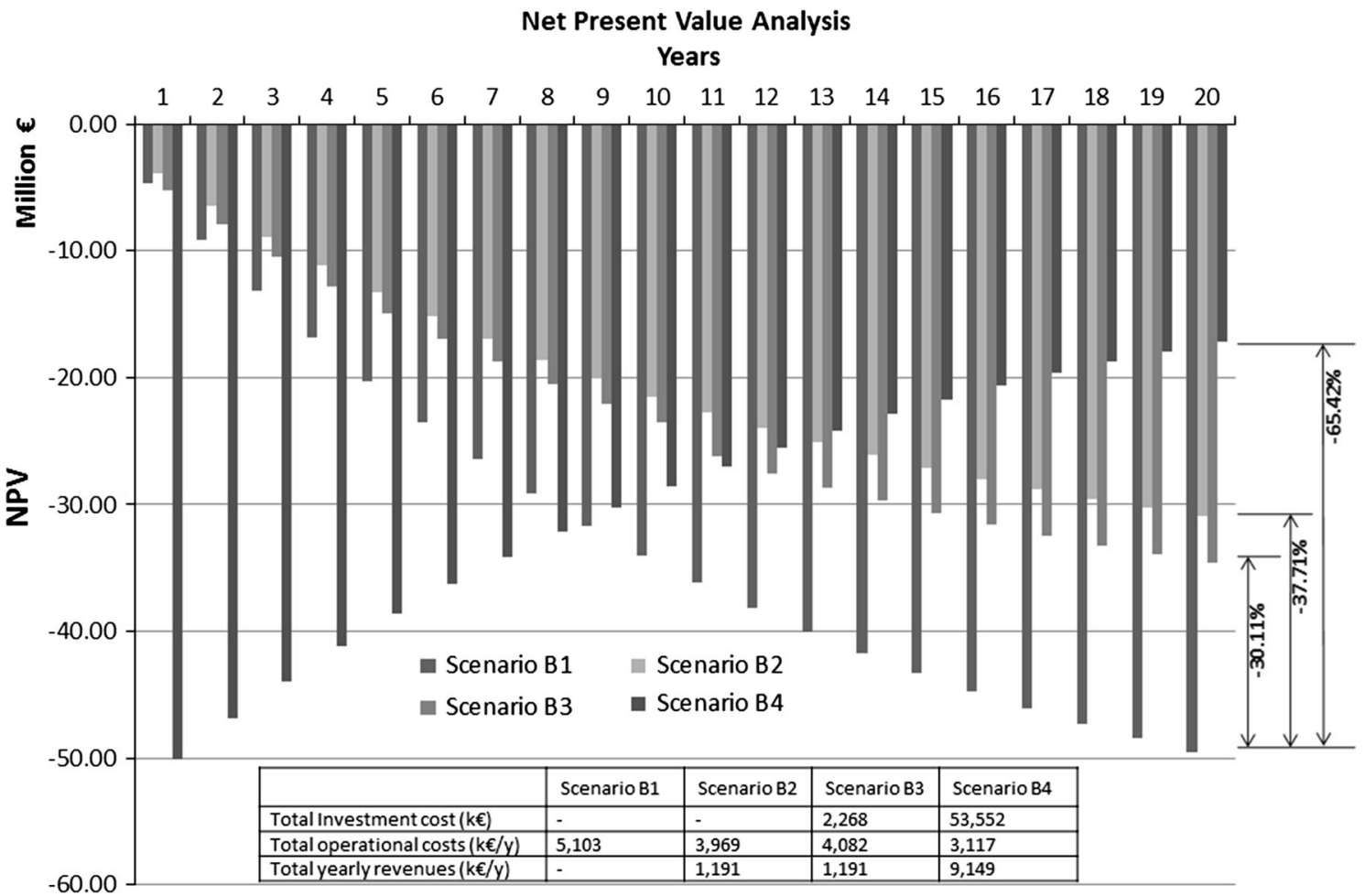

Fig. 6 NPV analysis for the second set of scenarios

substitute fuel. As presented in Fig. 6, there is a reduction in the loss regarding the management of RDF, compared with the base case scenario of no utilization. The results showed that any method adopted would decrease the loss from $30 \%$ up to $65 \%$, therefore increasing the plants' viability according to the present data of Greek market. Again, these results may 
differ depending on the changes in input MSW stream to be processed in the "EMA" plant.

\section{Conclusion}

Concluding, there are certain points that need to be noted. First of all, the high moisture content in the RDF leads to low heating value. Moreover, the chlorine content measured is believed to originate mainly from PVC. As far as mercury is concerned, there are some measured values that are very high comparing with the others. These samples are believed to have been contaminated from special streams of waste as batteries or light bulbs. The final classification of RDF according to CEN 343 is 4,3,1. As far as the studied scenarios are concerned, the most economically efficient for the viability of "EMA" is the scenario where the recovery of three high added value materials is separately collected. Regarding the management of RDF, the most suitable scenario, based on the present situation in Greece, seems to the mass incineration scenario for electricity production that will be sold in the grid.

Acknowledgments The financial support of ACMAR in the contract of "Sampling, analysis and classification of RDF produced in 'EMA' MBT plant" under the Grant number 9134/21-9-2009, is gratefully acknowledged.

\section{Abbreviations}

$\begin{array}{ll}\text { EU } & \text { European Union } \\ \text { MSW } & \text { Municipal solid waste } \\ \text { MBT } & \text { Mechanical-biological treatment } \\ \text { MRF } & \text { Material recycling facilities } \\ \text { RDF } & \text { Refuse-derived fuel } \\ \text { SRF } & \text { Solid recovered fuel } \\ \text { TDF } & \text { Tire-derived fuel } \\ \text { NCV } & \text { Net calorific value } \\ \text { NPV } & \text { Net present value }\end{array}$

ACMAR Association of Communities Municipalities of the Attica Region

and

\section{References}

Abeliotis K, Kalogeropoulos A, Lasaridi K (2012) Life cycle assessment of the MBT plant in Ano Liossia, Athens, Greece. Waste Manag 32:213-219

Agraniotis M, Nikolopoulos N, Nikolopoulos A, Grammelis P, Kakaras E (2010) Numerical investigation of solid recovered fuels' co-firing with brown coal in large scale boilers: evaluation of different co-combustion modes. Fuel 89:3693-3709

Caputo AC, Pelagagge PM (2002) RDF production plants: I design and costs. Appl Therm Eng 22:423-437

Chiemchaisri C, Charnnok B, Visvanathan C (2010) Recovery of plastic wastes from dumpsite as refuse-derived fuel and its utilization in small gasification system. Bioresour Technol 101:1522-1527

Cozzani V, Petarca L, Tognotti L (1995) Devolatilization and pyrolysis of refuse derived fuels: characterization and kinetic modelling by a thermogravimetric and calorimetric approach. Fuel 74:903-912

Dunnu G, Hilber T, Schnell U (2006) Advanced size measurements and aerodynamic classification of solid recovered fuel particles. Energy Fuels 20:1685-1690

Dunnu G, Maier J, Hilber T, Scheffknecht G (2009) Characterisation of large solid recovered fuel particles for direct co-firing in large PF power plants. Fuel 88:2403-2408

Dunnu G, Maier J, Scheffknecht G (2010) Ash fusibility and compositional data of solid recovered fuels. Fuel 89:1534-1540

EN 15402:2011 Solid recovered fuels: determination of the content of volatile matter

EN 15403:2011 Solid recovered fuels: determination of ash content

EN 15407:2011 Solid recovered fuels: methods for the determination of carbon $(\mathrm{C})$, hydrogen $(\mathrm{H})$ and nitrogen $(\mathrm{N})$ content

EN 15408:2011 Solid recovered fuels: methods for the determination of sulphur $(\mathrm{S})$, chlorine $(\mathrm{Cl})$, fluorine $(\mathrm{F})$ and bromine $(\mathrm{Br})$ content

EN 15400:2011 Solid recovered fuels: determination of calorific value

EN 15414-3:2011 Solid recovered fuels: determination of moisture content using the oven dry method-part 3: moisture in general analysis sample

EN 15411:2011 Solid recovered fuels: methods for the determination of the content of trace elements (As, Ba, Be, Cd, Co, Cr, Cu, Hg, $\mathrm{Mo}, \mathrm{Mn}, \mathrm{Ni}, \mathrm{Pb}, \mathrm{Sb}, \mathrm{Se}, \mathrm{Tl}, \mathrm{V}$ and $\mathrm{Zn}$ )

EN 15442:2011 Solid recovered fuels: methods for sampling

EN 15443:2011 Solid recovered fuels: methods for the preparation of the laboratory sample

Fellner J, Rechberger H (2009) Abundance of ${ }^{14} \mathrm{C}$ in biomass fractions of wastes and solid recovered fuels. Waste Manag 29:1495-1503

Fellner J, Aschenbrenner P, Cencic O, Rechberger H (2011) Determination of the biogenic and fossil organic matter content of refuse-derived fuels based on elementary analyses. Fuel 90:3164-3171

Garcia AN, Marcilla A, Font R (1995) Thermogravimetric kinetic study of the pyrolysis of municipal solid waste. Thermochim Acta 254:277-304

Grammelis P, Basinas P, Malliopoulou A, Sakellaropoulos G (2009) Pyrolysis kinetics and combustion characteristics of waste recovered fuels. Fuel 88:195-205

Henrich E, Burkle S, Meza-Renken ZI, Rumpel S (1999) Combustion and gasification kinetics of pyrolysis chars from waste and biomass. J Anal Appl Pyrol 49:221-241

Hernadez-Atonal FD, Ryu C, Sharifi VN, Swithenbank J (2007) Combustion of refuse-derived fuel in a fluidised bed. Chem Eng Sci 62:627-635

Hilber et al (2007) Advantages and possibilities of solid recovered fuel cocombustion in the European energy sector. Air Waste Manag Assoc 57:1178-1189

Kim S (2001) Pyrolysis kinetics of waste PVC pipe. Waste Manag 21:609-616

Lin K-S, Wang HP, Liu S-H, Chang N-B, Huang Y-J, Wang H-C (1999) Pyrolysis kinetics of refuse-derived fuel. Fuel Process Technol 60:103-110

Liu G-Q, Itaya Y, Yamazaki R, Mori S, Yamaguchi M, Kondoh M (2001) Fundamental study of the behaviour of chlorine during the combustion of single RDF. Waste Manag 21:427-433

Montejo C, Costa C, Ramos P, Marquez MC (2011) Analysis and comparison of municipal solid waste and reject fraction as fuels for incineration plants. Appl Therm Eng 31:2135-2140 
Ollila HJ, Moilanen A, Tiainen MS, Laitinen RS (2006) SEM-EDS characterization of inorganic material in refuse-derived fuels. Fuel 85:2586-2592

Sipsas K, Skiadi O, Tsakalou K (2008) Mechanical and biological treatment of municipal solid waste: the plant of mechanical sorting and composting of Athens. Solid biofuels: Green Practice in modern industry, National Technical University of Athens

Sorum L, Gronli MG, Hustad JE (2001) Pyrolysis characteristics and kinetics of municipal solid wastes. Fuel 80:1217-1227

Uson AA, Ferreira G, Vasquez DZ, Bribian IZ, Sastresa EL (2012) Estimation of the energy content of the residual fraction refused by MBT plants: a case study in Zaragoza's MBT plant. J Clean Prod 20:38-46

Wagland ST, Kilgallon P, Coveney R, Garg A, Smith R, Longhurst PJ, Pollard SJT, Simms N (2011) Comparison of coal/solid recovered fuel (SRF) with coal/refuse derived fuel (RDF) in a fluidised bed reactor. Waste Manag 31:1176-1183

Wan H-P, Chang Y-H, Chien W-C, Lee H-T, Huang CC (2008) Emissions during co-firing of RDF-5 with bituminous coal, paper sludge and waste tires in a commercial circulating fluidized bed co-generation boiler. Fuel 87:761-767 